\title{
Traumatic Dislocation of Three Major Joints in the Lower Limb: Management and Outcome
}

\author{
G. Maccagnano ${ }^{1,2}$, A. Notarnicola ${ }^{1}$, G. Sammarco ${ }^{2}$ L. Scialpi ${ }^{2}$, B. Moretti ${ }^{1}$ \\ 1 Orthopaedics Unit, Department of Basic Medical Science, Neuroscience and Sensory Organs, Faculty of \\ Medicine and Surgery, University of Bari, General Hospital \\ 2 Orthopaedic and Trauma Unit, SS. Annunziata Hospital
}

\author{
CORRESPONDING AUTHOR: \\ Angela Notarnicola \\ Orthopaedics Unit, Department of Basic \\ Medical Science \\ Neuroscience and Sensory Organs \\ Faculty of Medicine and Surgery \\ University of Bari, General Hospital \\ Place G. Cesare, 11 \\ 70124 Bari, Italy \\ E-mail: angelanotarnicola@yahoo.it
}

DOI:

10.32098/mltj.01.2020.21

LEVEL OF EVIDENCE: 5

\begin{abstract}
SUMMARY
Introduction. Traumatic knee dislocation is a serious lesion which represents an orthopaedic emergency. It is a rare condition that requires appropriate diagnosis - therapeutic iter. Case report. A 63 year old male was admitted to the emergency department after an agricultural vehicle accident in which his lower limbs were caught in a tractor. Clinical examination showed bilateral exposed knee dislocation. In addition there emerged right hip dislocation and composed acetabular fracture. There were no vascular arteries injuries, whilst there emerged an external popliteal sciatic nerve palsy to the left site. We performed the reduction manoeuvre revealing bilateral joint instability. For this reason the stabilization was made by external fixators. Due to right knee severe valgus instability, we performed medial collateral ligament reconstruction by intraosseous suture anchor using Leeds-Keio artificial implant after 1 month.

Conclusions. In our case, due to the involvement of three major joints and nerve palsy, we had to perform the reduction manoeuvre, exploration and suture of peroneal nerve and stabilization by the external fixator. The opportuneness of ligament reconstruction may be evaluated at a second step in relation to functional expectancy and skin condition of the donor site.
\end{abstract}

\section{KEY WORDS}

Knee dislocation; hip dislocation; instability; nerve palsy

\section{BACKGROUND}

Traumatic knee dislocation is a serious lesion which represents an orthopaedic emergency. It is a rare condition that requires appropriate diagnosis - therapeutic iter. The incidence has been reported as approximately $0.02-0.2 \%$ of orthopaedic lesions $(1,2,3)$. The variability in epidemiologic data maybe due to spontaneous reduction before arriving at the emergency department thus leading to missed diagnosis $(4,5)$. This injury is caused by high energy trauma which is responsible for forces in the antero-posterior direction, varus-valgus angulation and rotational component $(6,7)$. Knee dislocation, on the one hand, causes ligaments lesions and, on the other hand, leads neurovascular complications involving common peroneal or tibial nerve (19\%) and /or popliteal artery $(20 \%)(8)$. In the literature, the Authors suggest surgical management for irreducible dislocations or those in which there is joint instability and / or vessels-nerve complications onset. For the other cases, conservative treatment is recommended $(9,10)$.

\section{CASE PRESENTATION}

A 63 year old male was admitted to the emergency department after an agricultural vehicle accident in which his lower limbs were caught in a tractor. This study was conducted ethically according to international standards (11). Clinical examination showed bilateral knee dislocation, which was open to the left side. In addition, the left leg was internally rotated and slightly shortened. The skin was interrupted on both sides of the limbs but for the left leg there was an extension to the popliteal region (figure 1). There were no vascular arteries injuries, whilst there emerged an external popliteal sciatic nerve palsy to the left site. On the basis of these clinical elements we performed $\mathrm{x}$-rays. The exams 


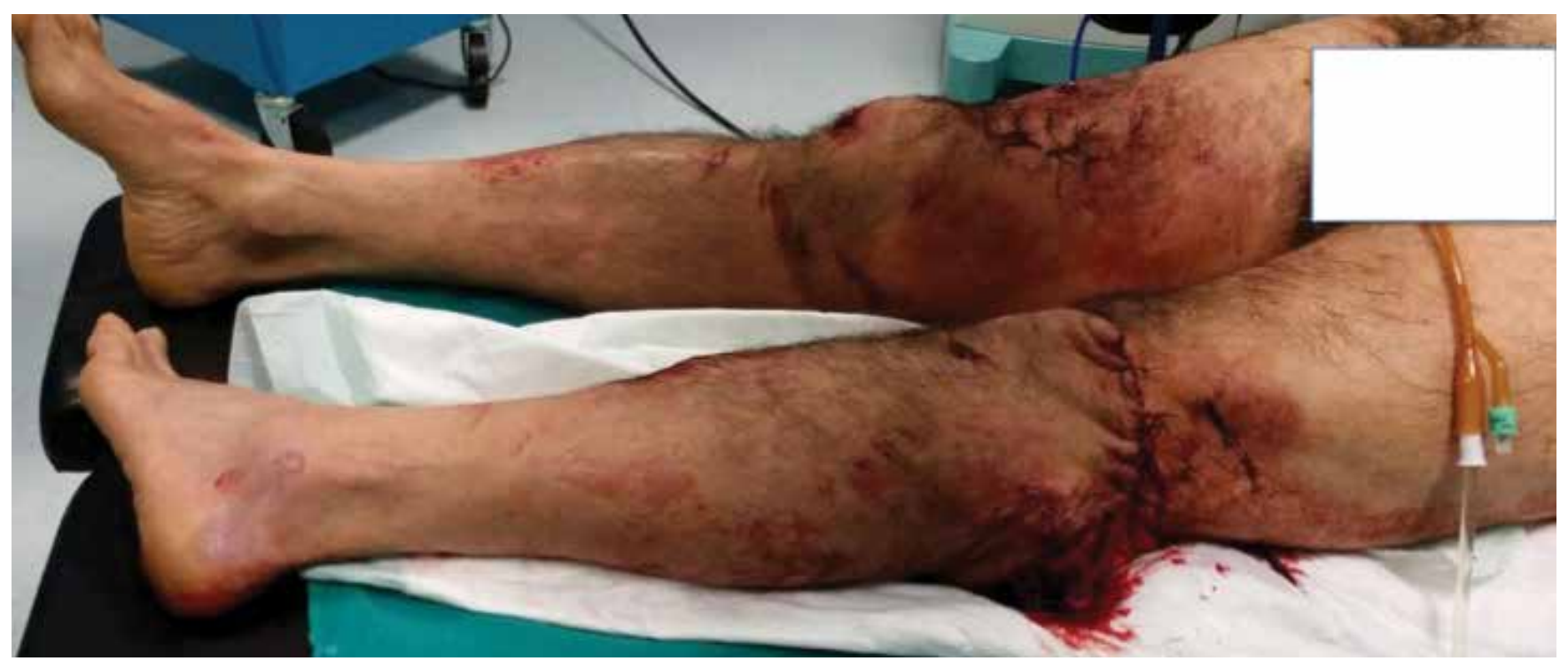

Figure 1. Clinical photo of bilateral knee exposed dislocation

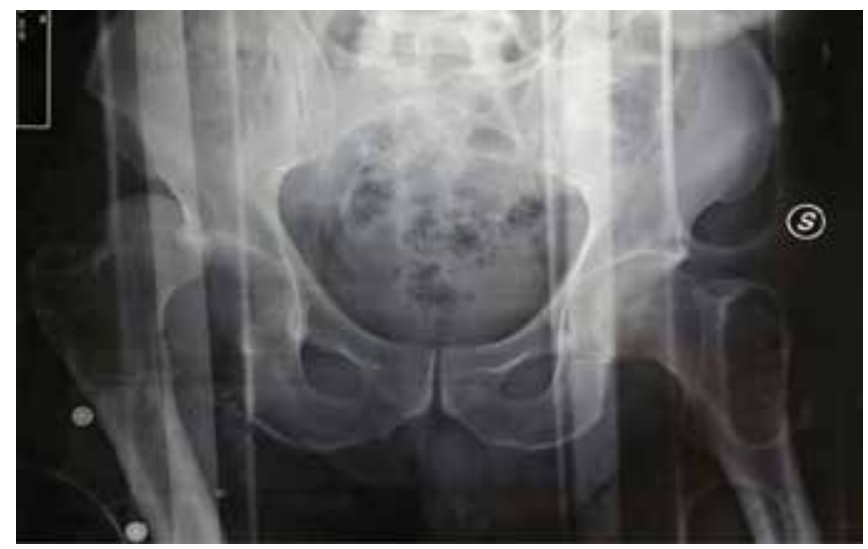

Figure 2. X-ray revealed right hip dislocation

confirmed the bilateral anterior knee dislocation. In addition there emerged right hip dislocation and composed acetabular fracture (figures 2, 3, 4). Immediately afterwards the patient underwent surgery to reduce the three dislocations and to stabilize the joint.

The orthopaedic surgeon performed the reduction manoeuvre revealing bilateral joint instability. For this reason there was performed bilateral stabilization by external fixators. A clinical and duplex ultrasound vascular evaluation was carried out in order to exclude arterial injury. Furthermore the surgeon completed the debridement of skin lesion and the suture of external popliteal sciatic nerve interruption. He was not allowed any weight bearing for four weeks. After 1 month, the patient underwent another operation in order to remove external fixators and to test knee joints stability. Due to right knee severe valgus instability, we performed medial collateral ligament reconstruction by intraosseous suture anchor using Leeds-Keio artificial implant (figures 5A, 5B). We chose to treat only the severe valgus instability of the right knee which would not have allowed him even to walk; as regards the central pivot both for age and for arthritic degeneration of the joints involved, we did not consider it useful to treat.

An regards the left knee, we removed completely the external fixator, allowing full weight bearing using a knee hinged brace. As for the right knee, a hinged knee brace locked in $30^{\circ}$ of flexion was used to avoid instability onset and to protect the suture. The patient was allowed to perform isometric exercises. One week later, the brace was unlocked and the knee was brought through a full range of motion passively and he began physical therapy. Four weeks later, he was able to use partial weight bearing with crutches. At 4 months after the accident, he could walk without crutches. His nerve palsy persisted notwithstanding there emerged an improvement in neurological skills. At 1 year after the trau$\mathrm{ma}$, we reported a development of heterotopic ossification (figures 6A-6B), without functional limitations (figure 7).

\section{DISCUSSION}

Knee dislocations are caused by high energy trauma. These injuries are a rare condition (12). Following initial trauma management, which involves the reduction manoeuvre, the attention may return to clinical evaluation. At the begin- 


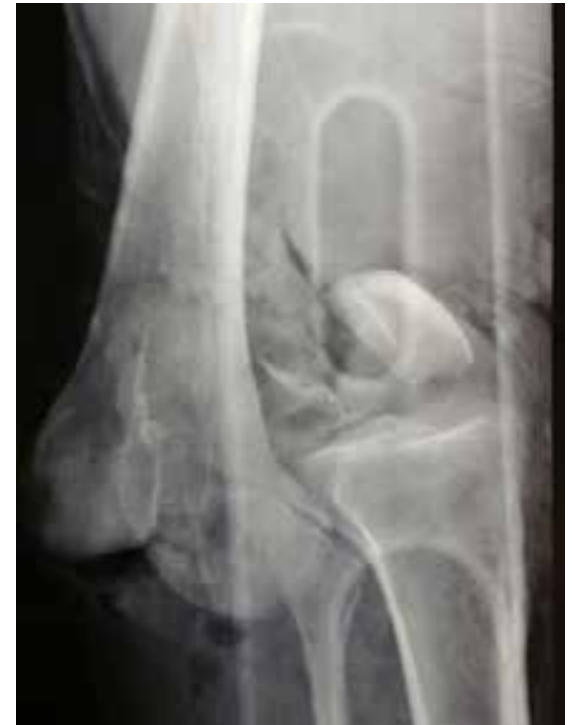

Figure 3. X-ray: left knee dislocation

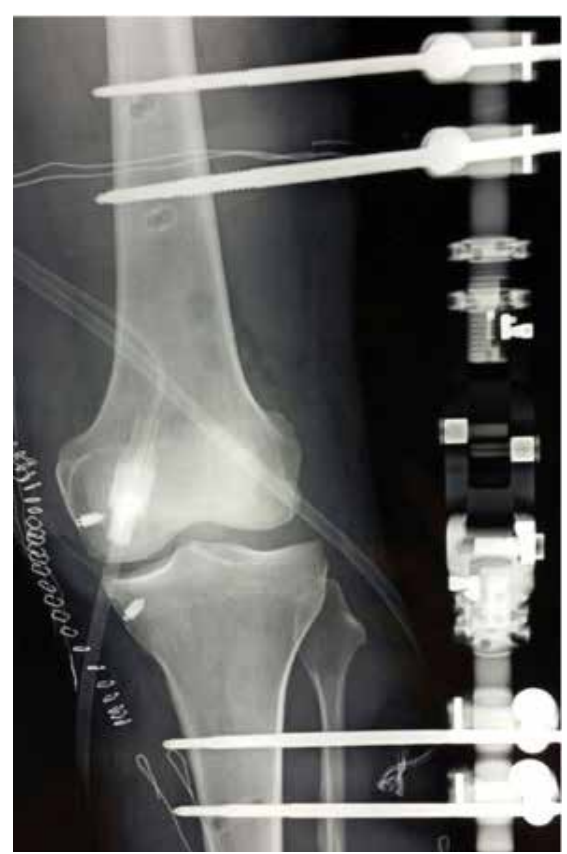

Figure 5A. X-ray: AP view

ning the examination has to document vascular and /or neurological impairment. Afterwards, it is necessary to evaluate joint stability performing different tests, though these are difficult to carry out in the

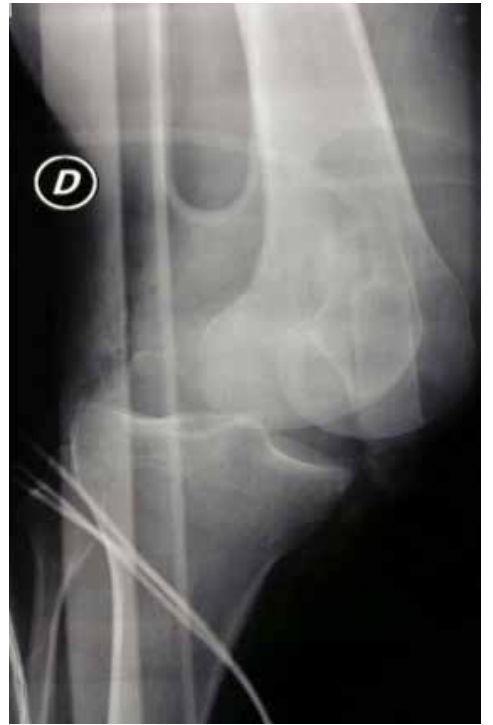

Figure 4. X-ray: right knee dislocation

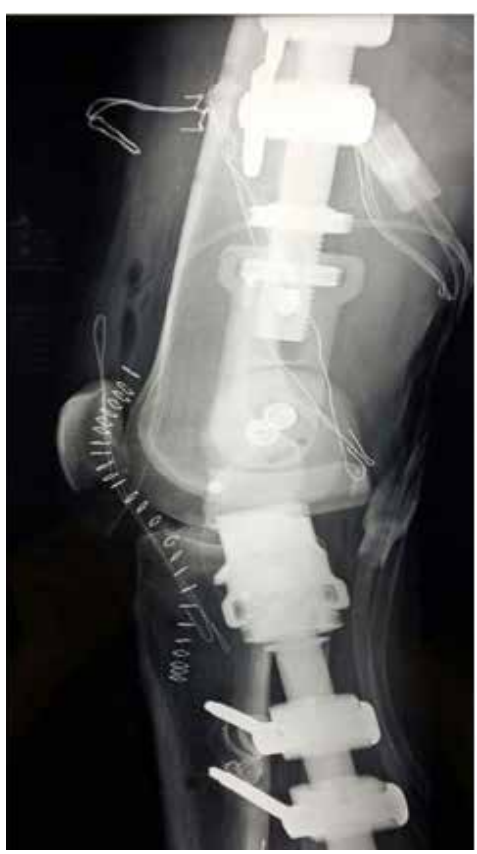

Figure 5B. X-ray: LL view

acutely and are potentially unreliable (13). After the initial management, the surgical decision making process has to consider different factors. The first is the vascular integrity of the limb which requires the surgical repair and then bone stabilization (14) The second factor is the association between knee dislocation and open fractures (15). The third factor is represented by irreducible dislocation of the knee $(16,17)$. Knee dislocation is usually treated in a cast or brace for weeks. According to recent bibliography, the surgical option plays the main role in dealing with complications associated to immobilisation and in restoring joint stability (18). According to literature, the surgical option has to represent the main strategy in terms of recovery times and the restoring of range of motion $(19,20)$.

In our case, we had to consider operative management the first option in consideration of tissue exposition and nerve palsy. In fact, we performed the knee dislocations reduction stabilizing the joints by external fixator to manage the joint instability. On the one hand, there emerged a critical soft tissue situation associated to external debris; on the other hand, the laxity tests are not reliable in the acute phase. For this reason we decided to postpone the definitive treatment in order to allow the wound and soft tissue to recover and to assess the subsequent joint stability. Delaying reconstruction after injury to allow for soft tissue improvement could reduce the arthrofibrosis and complication and at the same time leads better surgical results. The Authors were in agreement with literature as regards delaying the surgery to obtain better results $(21,22)$.

In our case report, at 1 month after the external fixator removal, there emerged a valgus instability to the right knee. Notwithstanding we know the importance to reconstruct the central pivot for biomechanical stability, both for age and for arthritic degeneration of the joints involved, we did not consider it useful to treat. We chose to treat only the severe valgus instability of the right knee which would not have allowed him even to walk. The synthetic implant was used to augment the medial collateral ligament in order to cope with degenerative tissue of medial compartment and collateral structure rupture $(23,24)$. 


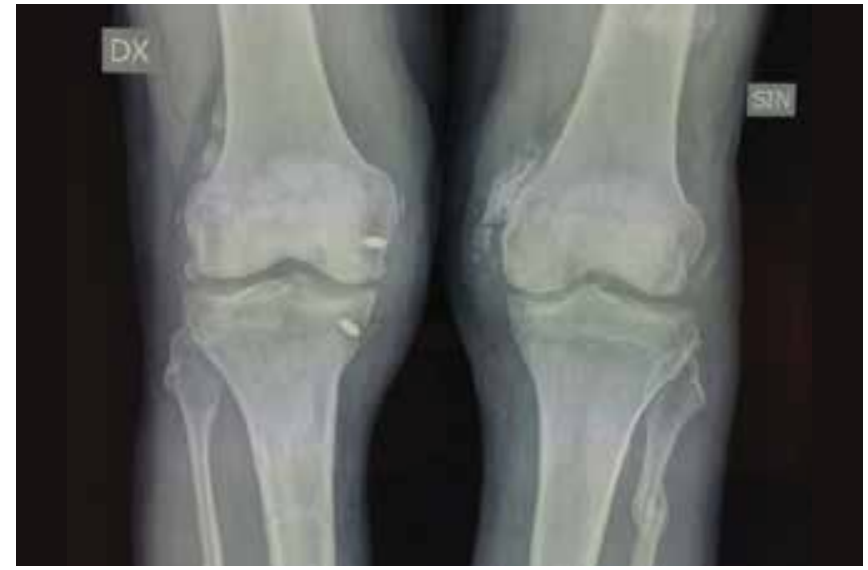

Figure 6A. X-ray AP view at 1 year of follow-up

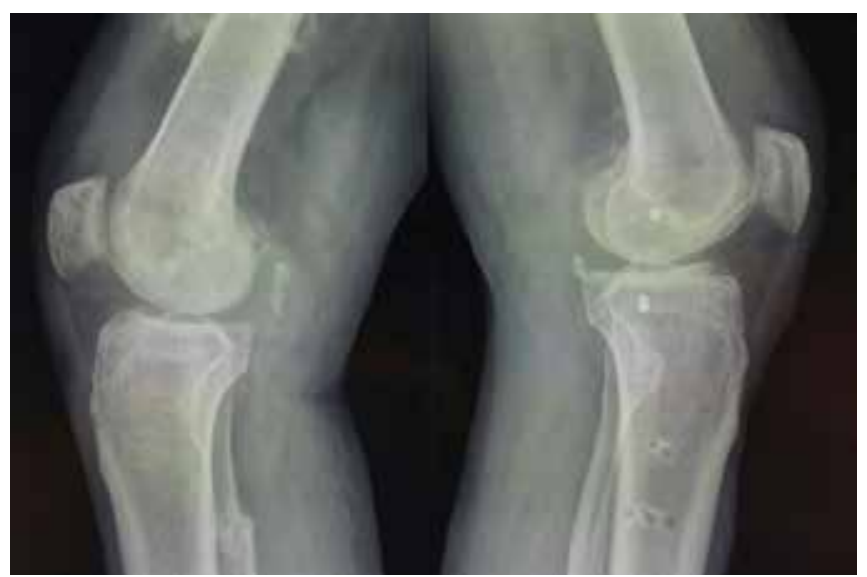

Figure 6B. X-ray LL view at 1 year of follow-up

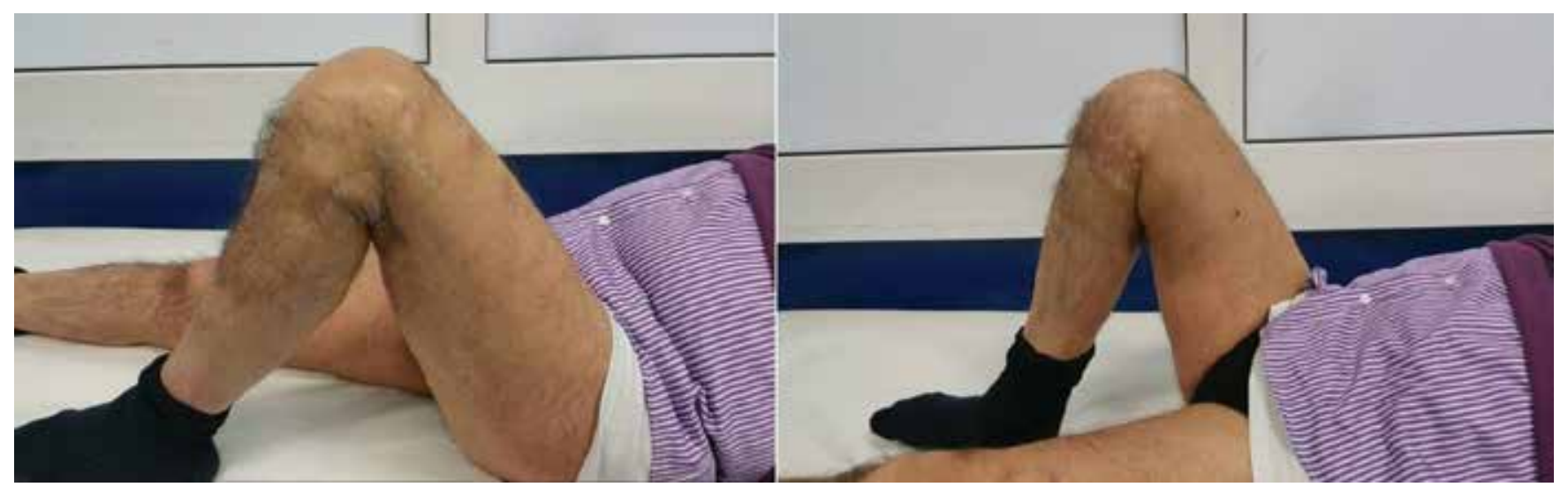

Figure 7. Complete functional recovery after 1 year

Furthermore, in consideration of previous scars and in order to avoid any eventual skin necrosis, the Authors preferred not to perform another skin incision in the donor site of the semitendinosus tendon. Another consideration was that semitendinosus tendon might well be needed at later date to reconstruct the anterior ligament.

According to literature, the choice of artificial ligament is linked to age, functional requirements of the patient, time of surgery and size of anatomic structure. Hamido et al. in 2015 analysed the results obtained by comparison of synthetic implant versus a four strand hamstring tendon graft in chronic cruciate ligament. The Authors reported the better early results of short and small sized artificial reinforcement system (25). As regards the rehabilitation, the complexity of the case due to the involvement of both knees and sciatic nerve palsy to the left site. The goal of post operative rehabilitation is to restore range of motion reducing the risk of joint instability. The delaying surgical treatment of right side, allowed to perform the rehabilitation program of the two knees separately. In fact, the Author treated before the left side using a knee hinged brace after not weight bearing for four weeks; as regards the right sides the rehabilitation program started after the surgery reconstruction. This timing allowed us to obtain good functional outcomes.

The limitation is the uniqueness of the case. The strength point is that this case is the first treated in this way.

\section{CONCLUSIONS}

Knee dislocation is a rare a severe condition. In our case, due to the involvement of three major joints and nerve palsy, we had to perform the reduction manoeuvre, exploration and suture of peroneal nerve and stabilization by the external fixator. The opportuneness of ligament reconstruction may be evaluated at a second step in relation to functional expectancy and skin condition of the donor site. 


\section{ACKNOWLEDGEMENTS}

The authors thank Mr Brian John Molloy, B.A., for language revision.

\section{CONFLICT OF INTERESTS}

The authors declare that they have no conflict of interests.

\section{REFERENCES}

1. Darcy, Genevieve, Elton Edwards, and Raphael Hau. Epidemiology and outcomes of traumatic knee dislocations: Isolated vs multi-trauma injuries. Injury. 2018; 49(6): 1183-1187.

2. Burrus, M. Tyrrell, Brian C. Werner, Jourdan M. Cancienne, and Mark D. Miller. Simultaneous bilateral multiligamentous knee injuries are associated with more severe multisystem trauma compared to unilateral injuries. Knee Surgery, Sports Traumatology, Arthroscopy. 2015; 23(10):3038-3043.

3. Moura, Diogo Lino, José Pedro Marques, Pedro Matos, Luís Antunes, Óscar Gonçalves, and António Albuquerque. Bilateral knee dislocation with associated bilateral popliteal arterial injury. Revista brasileira de ortopedia. 2018; 53(2): 248-251.

4. Swenson TM. Physical diagnosis of the multiple-ligament-injured knee. Clin Sports Med. 2000; 19(3): 415-23.

5. Hegyes MS, Richardson MW, Miller MD. Knee dislocation. Complications of nonoperative and operative management. Clin Sports Med. 2000; 19(3): 519-43.

6. DuBois, Ben, William H. Montgomery Jr, LCDR Robert P. Dunbar, and Jens Chapman. Simultaneous ipsilateral posterior knee and hip dislocations: case report, including a technique for closed reduction of the hip. Journal of orthopaedic trauma. 2006; 20(3): 216-219.

7. Urgüden M, Bilbaşar H, Ozenci AM, Akyildiz FF, Gür S. Irreducible posterolateral knee dislocation resulting from a low-energy trauma. Arthroscopy. 2004;20 (Suppl 2): 50-53.

8. Medina, Omar, Gabriel A. Arom, Michael G. Yeranosian, Frank A. Petrigliano, and David R. McAllister. Vascular and nerve injury after knee dislocation: a systematic review. Clinical Orthopaedics and Related Research ${ }^{\circledR}$ 2014; 472(9): 2621-2629.

9. Liow RY, McNicholas MJ, Keating JF, Nutton RW. Ligament repair and reconstruction in traumatic dislocation of the knee. J Bone Joint Surg Br. 2003;85:845-851.

10. Howells NR, Brunton LR, Robinson J, Porteus AJ, Eldridge JD, Murray JR. Acute knee dislocation: an evidence based approach to the management of the multiligament injured knee. Injury 2011; 42(11): 1198-204.

11. Padulo J, Oliva F, Frizziero A, Maffulli N. Muscles, Ligaments and Tendons Journal - Basic principles and recommendations in clinical and field Science Research: 2018 update. MLTJ 2018; 8(3): $305-307$

12. A. Robertson, R. W. Nutton, and J. F. Keating, Dislocation of the knee. JBJS Br 2006; 88 (6): 706-711.

13. Deveci A, Cankaya D, Yilmaz S, Özdemir G, Arslantaş E, Bozkurt M. The arthroscopical and radiological corelation of lever sign test for the diagnosis of anterior cruciate ligament rupture. Springerplus. 2015; 4: 830.

14. Wascher DC, Dvirnak PC, DeCoster TA. Knee dislocation: initial assessment and implications for treatment. J Orthop Trauma 1997; 11(7): 525-9.

15. Green RN, Pullagura MK, Holland JP. Irreducible fracture-dislocation of the knee. Acta Orthop Traumatol Turc. 2014:48(3):363-6

16. Gu MQ, Deng L, Liu Y. Posterolateral dislocation of the knee joints: analysis of 9 cases. Chin J Traumatol. 2004;7:210- 216.

17. Solarino G, Notarnicola A, Maccagnano G, Piazzolla A, Moretti B. Irreducible posterolateral dislocation of the knee: a case report. Joints. 2015 Apr-Jun; 3(2): 91-96.

18. Wong CH, Tan JL, Chang HC, Khin LW, Low CO. Knee dislocations-a retrospective study comparing operative versus closed immobilization treatment outcomes. Knee Surg Sports Traumatol Arthrosc 2004; 12(6): 540-4.

19. Dedmond BT, Almekinders LC. Operative versus nonoperative treatment of knee dislocations: a meta-analysis. [Erratum appears in Am J Knee Surg 2001 Autumn; 14(4): 220]. Am J Knee Surg 2001; 14(1):33-8.

20. Peskun CJ, Whelan DB. Outcomes of operative and nonoperative treatment of multiligament knee injuries: an evidencebased review. Sports Med Arthrosc Rev 2011; 19(2): 167-73.

21. Levy BA, Dajani KA, Whelan DB, Stannard JP, Fanelli GC, Stuart MJ, Boyd JL, MacDonald PA, Marx RG. Decision making in the multiligament-injured knee: an evidencebased systematic review. Arthroscopy 2009; 25(4): 430-8.

22. Fanelli GC, Edson CJ. Arthroscopically assisted combined anterior and posterior cruciate ligament reconstruction in the multiple ligament injured knee: 2- to 10-year follow-up. Arthroscopy 2002; 18(7): 703-14.

23. Randy M, MacDonald PB.. Anterior cruciate ligament reconstruction: a look at prosthetics-past, present and possible future. McGill Journal of Medicine 11.1 (2008): 29.

24. Inoue NEM, Sugiura H.. Ultrastructural study of the extra-articular Leeds-Keio ligament prosthesis. Journal of clinical pathology 2005; 58 (6): 665-666.

25. Hamido F, Al Harran H, Al Misfer AR, El Khadrawe T, Morsy MG, Talaat A, Elias A, Nagi A. Augmented short undersized hamstring tendon graft with LARS ${ }^{\circledR}$ artificial ligament versus four-strand hamstring tendon in anterior cruciate ligament reconstruction: preliminary results. Orthop Traumatol Surg Res. 2015;101(5):535-8 